\title{
Comparing Literacy Instruction within China and the United States
}

\author{
Roberta Simnacher-Pate (Corresponding author) \\ Texas A\&M University-Corpus Christi \\ Curriculum \& Instruction, 6300 Ocean Drive, ECDC 240, Corpus Christi, TX, 78412, USA \\ Tel: 1-361-825-3658 E-mail: robin.pate@tamucc.edu \\ Evan Ortlieb \\ Texas A\&M University-Corpus Christi \\ Curriculum \& Instruction, 6300 Ocean Drive, ECDC 219-H, Corpus Christi, TX, 78412, USA \\ Tel: 1-361-825-3661 E-mail: evan.ortlieb@tamucc.edu
}

Earl H. Cheek, Jr.

Louisiana State University

Department of Educational Theory, Policy, \& Practice, 223 Peabody Hall, Baton Rouge, LA, 70803, USA

Tel: 1-225-578-6867 E-mail: echeek@1su.edu

Received: May 9, 2011

doi:10.5539/elt.v4n4p3
Accepted: May 26, 2011

Published: December 1, 2011

URL: http://dx.doi.org/10.5539/elt.v4n4p3

\begin{abstract}
The presence of multilingual learners places multifarious demands upon classroom educators to properly select appropriate research-based and functional methods, materials, and assessments to guide children's literacy development. Researchers aimed to investigate whether universal teaching methods, materials, assessments, concerns, and problems exist within countries around the world, albeit disguised in a myriad of languages. As a plethora of questions continued to arise, an opportunity was seized to explore the educational similarities and differences of elementary school literacy instruction between China and the United States specifically.

Qualitative methods of investigation were utilized in this case study to determine that Chinese schools in Beijing utilized teacher-centered methods of instruction, structured learning environments, and whole-class leveled instruction in departmentalized settings. These principles promote educational development, even though schools in the United States are moving from that model to ones more individualized, aimed at preventing student failure and emphasis is placed on remediation of difficulties.
\end{abstract}

Keywords: China, United States, Literacy, Education, Elementary, Comparative

\section{Introduction}

Educational systems worldwide aim to make didactic improvements every year; however, these must be founded chiefly with the interest of student learning in mind. These ambitions and aspirations held by educational institutions are easier to establish than to implement and therefore, schools constantly struggle to advance their instructional abilities. The search for more effective research-based methods in the United States most often originates in its own laboratory schools; meanwhile, other countries search globally for improved methods. In turn, other countries continue to elevate their ranking on the Program for International Student Assessment (PISA) when compared globally with the United States. In 2009, for instance, Chinese students ranked first of 34 participatory countries in reading, math, and science, far outpacing their American peers (PISA, 2009).

At the end of the $20^{\text {th }}$ century, China looked toward other countries including the United States for models of effective education (MOE, 2005). Since then, its reforms have sparked gains in educational testing scores far surpassing students in the United States. A closer examination is needed to investigate Chinese literacy instruction, including its similarities and differences to U.S. elementary schools. This study's findings will be relevant for U.S. schools to glean information on accelerating student learning so they can remain competitive in a $21^{\text {st }}$ century global community. 


\section{Historical Overviews}

\subsection{Chinese education/literacy}

In 1949 the founding of the People's Republic in China spurred new energy with a focus on national importance for education to build a strong nation. Later in 1978 an "open up" policy released China from its destructive grips and began an emergent path to new realms. During the late $20^{\text {th }}$ century, various educational reforms, policies, and ratifications were constructed and committees were built with the unending focus to invigorate China's basic education system. According to the Ministry of Education in China (2005):
[D] uring the past 50 years since the founding of the People's Republic of China, basic education in China has gained tremendous achievements. In 2002, there were 111,800 kindergartens with an enrollment of 20,360,200 young children. By 2002, there were altogether 456,900 primary schools with an enrollment of 121,567,100 students and the net enrollment rate of primary schools had reached 98.58\%. 97.02\% of the graduates enjoyed the access to junior secondary schools and the full-time teacher in primary schools had reached 5,778,900. In addition, there were 65,600 junior secondary schools with an enrollment of 66,874,300 students and the net enrollment rate of junior secondary schools had been raised to 90\%. Those schools employed totally 3,467,700 full-time teachers and 58.3\% of the junior secondary graduates continue their study in senior secondary schools. By the end of 2002, the Nine-Year Compulsory Education (NYCE) had been universalized in the area where 90\% of the population inhabits the highest rate among the E-9 countries. (p. 1)

In turn, a country that encompasses 3.7 million square miles and houses 1.3 billion in population recognized its heavy demand for quality and equal education and has been committed for the last two decades.

Reforms are created to promote educational growth; however, the methods, instructions, assessments, and contents are central to a nation's educational system. Being able to read and write one's language proficiently is an accurate measure of a nation's literacy success. Investigators continued to ponder if the methods used as the impetus for China's success are universal across the face of the earth. Li and Rao (2005) describe the orthographical differences between the teaching of English and Chinese by saying, "Unlike the English language, the written unit in the Chinese language, the character, indicates both meaning and phonology" (p. 236). They further reveal that Chinese children have more difficulty understanding and replicating Chinese characters than their American counterparts who use only 26 symbols. However, YongBing (2005) studied the use of Pinyin, a 26 roman letter writing system that was "adopted by the Chinese government in 1958 as an official system parallel to Chinese character script. He reported, "It was subsequently recognized by the International Organization of Standardization (ISO) in 1982 as the standard for the spelling of proper Chinese names (people, places, and China specific terms) in non-Chinese texts for international communication" (p. 401). Yet the Ministry of Education in China has a current directive in effect to not begin formal education until after the age of six because "...early literacy teaching was a waste of time and was concerned that it could be counterproductive" (Li \& Rao, 2005, p. 237).

Mee and Moi (1999) edited a collection of papers that reflected a universal concern for Chinese literacy attainment. Chern (1999) revealed that "the teaching of Chinese has traditionally been associated with rote learning and teacher dominated instruction" (p. 12). She presented an overview of the various methods for reading instruction as modeled in the United States, chiefly reflecting on the whole-language versus phonics-based approaches along with the balanced literacy model that is currently in fad. Chern's study observed classes that "were full of student-teacher and student-student interactions; that is, these teachers actively engaged students in expressing and sharing ideas" (p. 25).

\subsection{U.S. education/literacy}

The United States Department of Education was created in 1980 to provide equal access to education and to promote educational excellence throughout the nation. In the last decade (2000-2009), significant changes to the goals and provisions of the United States Department of Education have had tremendous impacts on virtually every public school in America. Aimed at closing the achievement gap between economically challenged and minority students and their peers, the No Child Left Behind Act of 2001 (NCLB) established an educational reorganization, which has had more affect on schools than any other since the Elementary and Secondary Education Act (ESEA) in 1965. As one of President George W. Bush's primary agendas, this educational reform has four key components: "stronger accountability for results, expanded flexibility and local control, expanded options for parents, and an emphasis on teaching methods that have been proven to work" (NCLB, 2002). Raising the expectations of every public school in America was central to the foundation of NCLB. 
In particular, NCLB "chang[ed] the literacy climate of classrooms and schools ... the impact of [the] law is being felt by school districts and schools receiving Reading First funds" (Stewart, 2004, p. 732). This act of legislation focuses on five components of reading instruction: phonemic awareness, phonics, vocabulary, fluency, and comprehension. U.S. Secretary Rod Page explains that the intent of "this bipartisan act is to build upon and enhance accountability systems that States have been developing since, or prior to, the 1994 reauthorization of the ESEA Act" (2002, para. 1). No Child Left Behind also increased federal financial support for reading in particular from $\$ 300$ million in the fiscal year 2001 to over $\$ 900$ million in 2002; however, these funds could only be designated to methods of reading instruction that were scientifically proven. Within 12 years of its enactment, every public school in America is required to meet or exceed these standards. The federal government's enactment of NCLB was intended to assist educators provide better instruction so students could improve academically; its overall impact is still up for debate today (2007).

\subsection{Who is accountable for student learning?}

Within this era of high-stakes testing and accountability, less is often seen as more. No longer is learning valued as an instructional purpose, but only seen as a stepping stone for test scores and accountability (Campbell, 2002). Having students learn information only when it is somehow relevant to formalized testing seems arbitrary. Although the age of "teacher knows best" is currently out of favor with most funding sources, elementary teachers still have considerable control regarding what happens in their classrooms. Students spend almost all of their time in the classroom, so it goes without saying that teachers have the ability to greatly impact students' lives both positively and negatively. Heller (2006) says, "The art of teaching requires wide-ranging techniques that are responsive to individual student capacities and needs" (p. 358). Many times, educational matters such as setting and reaching goals, individualizing and adapting lessons, as well as varying and combining instructional styles are solely at the teacher's discretion (Williams \& Bauer, 2006). The classroom instructor also controls in large degree how these concepts and others like modeling, assessment, verbal communication, and classroom management are implemented.

Although teachers have copious responsibilities, there are no authentic instruction manuals for accomplishing these tasks (Collins \& Cheek, 2000). This is why it is commonly thought that the single most influential factor of effective literacy instruction is "the alignment between actual instructional practices used in the classroom and the depth of knowledge teachers have of the underlying concepts that support the use of innovative practices" (Smith, Baker, \& Oudeans, 2001, p. 9). Inevitably, there are great disparities between effective teachers with successful practices and ineffective teachers who fail with these responsibilities.

With that said, there are several other characters in the school setting who also contribute to the effectiveness of a school's functionality including the school board members, administrators, specialists, office workers, et cetera. Ideally, these members aim to ensure that every child be given the necessary appropriations and instruction to become educated. Each of these factors contributes to a school's overall effectiveness in preparing its students for future education, careers, and life in general. However, for the purposes of this study, classroom teachers and principals are the sole participants; this is due to the fact that these two entities contribute most closely to how students are instructed on a daily basis.

\subsection{Significance of study}

The purpose of this qualitative case study is to describe classroom instructional strategies, methods, and materials used to assist in the educational advancement for Chinese elementary and middle school students at two invitational campuses, Beijing Yumin Primary School and Beijing Qianmen Foreign Language School, to then compare with schools in the United States. A review of literature determined that no previous studies have been published since the 2009 PISA Report on comparative aspects of schools between the United States and China. Comparisons are needed to further analyze these settings using research-based methods of investigation to uncover if there are universal instructional methods, materials, assessments, and strategies across national borders.

\section{Methods}

A qualitative research approach was used to explore the school experiences of students and the schools' infrastructures that are located in China and in the United States. Lincoln and Guba (1985) describe the purpose of a qualitative study is to "accumulate sufficient knowledge to lead to understanding" (p. 227). Therefore this case study presented the opportunity to compare elementary schools that are oceans apart, allowing these researchers to reflect upon the data collected. A second approach of data analysis, as presented by Strauss and Corbin (1990), was utilized to accurately describe the situation before rebuilding the data into a genuine acknowledgeable report of current educational processes for universal students. Investigators employed the term 'interpretative-descriptive' research as coined by Belenky and et al (1986), as they progressed through the data analysis as qualitative researchers. As human instruments, we were aware of Patton's (1990) and others' process called Epoche and became very sensitive 
to possible "prejudices, viewpoints, or assumptions" (Katz, 1987, p. 36) as the nature of Chinese students was investigated; it was necessary to recognize that this culture and language were different from our own. In turn, a need for reflexivity arose as "the personal-self becomes inseparable from the researcher-self” (Creswell, 2003, p. 182).

The method of qualitative data collection places researchers as participant observers, as noted by Patton (1990) as a method of choice. As delegates in attendance, researchers maintained reflective journals along with documentation of field notes of classroom observations and open-forum discussions among professionals, both American and Chinese, as we collected data of the events in real time as they unfolded. These authentic documents have become part of the data collection and analysis process. Due to the use of field notes and observations, unpredictable discoveries emerged; therefore just as Lincoln and Guba (1985) advised, the parallel use of an emergent research design was documented as the study progressed. Our presence as observers was not an influential factor as we were among 50 observers; though we were the only ones documenting actions, times, and communications. Due to time limitations, in-depth interviews were not possible; however, the documentation of group interviews was maintained as a large group of American educators periodically asked questions to a much smaller population of Chinese contingency. Investigators sought to capture a profound snapshot of Chinese students and their teachers in the culture of which they thrive. The activating questions for these group discussions or interviews were not prepared in advance; instead they were inclusive of spontaneous questions that included both open- and close-ended questioning strategies that materialized to generate the participants' description of their experiences. Researchers allowed the participating delegates to generate their own questions as we documented the questions and responses, enveloping the American contingency within our study. In addition to extensive documentation of observations, photographs and short video clips captured events throughout the day.

Gaining access into the school settings was simplified, as we were members of the People to People Ambassadors' Program with the Reading and Literacy Delegation. The cultural exchange program leaders set and prepared the selected sites so each of the two schools received the delegation with welcoming arms to share, show, and discuss openly their current educational status along with their own professional concerns. These sites were very inviting to an international exchange of communication, since the People to People Ambassadors' Program has been in existence for 50 years since President Eisenhower recognized the importance of its mission-to develop personal exchanges and firsthand experiences with other cultures.

The two elementary schools were selected based on convenience sampling and therefore, this study represents a case study approach of schools affiliated with the People to People program in Beijing, China. A national guide was available to minimize the language barriers between China and the United States, serving as a language interpreter and cultural advisor.

Coding over 50 pages of handwritten, documented notes into themes followed the data collection phrase of investigation. After multiple examinations of the field notes transpired to create a high level of inter-rater reliability, portions of the reflective journal entries were also used to highlight events Chinese participants' experiences and stories. Data analysis yielded 'classroom management' and 'instructional styles' as initial categories of investigation along with morning exercise programs.

\subsection{Settings}

As American educators who have or currently work in rural public institutions, we set the stage for comparison by examining the demographics of our own local school district. One district in particular encompasses pre-kinder through twelfth grades. This elementary school in the United States currently registers an approximate attendance of over 300 students, while each of the other two campuses, middle and high school, are average approximately 200 students per campus. The school district's population is low socio-economic and consists of about $68 \%$ Hispanic, $28 \%$ Anglo, and 4\% Black; it has been operating U.S. Title 1 funds for several years.

On the other hand, the US-China Educators Exchange (2006) describes its school as the following: Beijing Yumin Primary School was established in 1949 and is one of the key primary schools in Beijing and was once the Primary School for the Children of Officials from Ministry of Finance. ... [In] 1961, the school became a boarding school for the children of governmental officials. In 1974, the school started the enrollment of the children of foreign experts from Japan, Cambodia, Laos, Sri Lanka, Italy, Albania, etc. (p. 47)

In 1995, Yumin started its Talented and Gifted Pupil's Education Experiment. It has more than 120 teachers and staff members, as well as 1,700 pupils in 49 classes. The school boasts of class size reduction since 1998; however, there are still 30-35 students per class. The school has four school buildings that vary in levels from 3 to 6 stories in stature that surround the demarcated exercise area, creating an enclosed campus while located in low-income 
housing district. Most of the students are transported to school by their parents and few students walk home. There were no signs of bicycles around the premise of the school at this particular visit.

The second facility, Beijing Qianmen Foreign Language School, was founded in 1996 and "is a private-operated school with official supports featuring foreign language education" (US-China Educators Exchange, 2006, p. 48). Located 150 meters away from Tian Anmen Square, it is equipped with advanced modern teaching facilities. All the classrooms are equipped multimedia equipment and the school maintains a television station. Chemistry, biology, and physics labs provide students ranging from grades 7 through 9 with hands-on equipment/experiences to develop and test hypotheses in evaluative studies. The school is located along a residential area and numerous bicycles were parked outside the school gates indicating that many of the students must ride them to school; thus they must live relatively nearby. Construction recently commenced to tear down older buildings in the area, making way for newer structures. There are people still living in partial forms using sheets for doors and outdoor heating for warmth and lanterns for lighting. The students' classrooms are well lit with natural lighting from large windows and spanned four floors. The rear of the school leads to a single level building where the delegates met, discussed, and ate lunch. A pagoda and small garden were found between two buildings, leading in the opposite direction towards the basketball courts, hosting eight netted hoops, where morning exercises took place.

\section{Results}

Classroom observations revealed similar behaviors within the two schools in Beijing. Instruction was teacher centered; yet students were allowed pair/share and whole-group response interactions. All three departmentalized teachers had access to and used PowerPoint presentations for lesson delivery and student interaction. The elementary teacher supported this delivery with colorful teacher-made characters that were used during the lesson as they were teaching Mandarin words and symbols. The first grade students in unison kinesthetically wrote stroke placement for Chinese character writing in the air, while others used magnetic stroke strips to properly place characters within a prepared template. After placement, students tried to correct their peers' work.

The middle school teacher apparently assigned a student to create a PowerPoint presentation as a follow up to the thematic reading lesson about endangered species, as one student volunteered to present her slides at the end of the teacher's lesson. In similarity to Chern's (1999) discovery, students were active at various points in the lesson and participated with the teacher. We noted that the elementary students raised their hands for permission to speak and stood to speak while middle school students were more reserved and only three different girls spoke independently during the course of the class period. The teacher was having a difficult time soliciting participation. We noted that when discussion of homework commenced, students pulled notebook paper from the texts. Even though this was a reading class instructed in English, the students' homework was done in Chinese characters. Researchers posited that student participation might have been hindered by their lack of mastery of English speech amidst an American audience.

Consumable workbooks were a common feature as the teacher relied on whole-class participation and maintained all students at one instructional level concurrently. The first grade and middle school classes wrote in their texts during these particular observations. Grade 1 consisted of forming the proper Chinese character strokes and the teacher displayed certain children's work on the Elmo projector for class critique while the middle school responded to main idea and key fact questions to a particular passage. Chern's (1999) study also noted the use of workbooks, stating that workbooks were highly regarded and led the lesson step by step. Because the two elementary classrooms were highly structured, other forms of authentic literature were not observed; the middle school lacked opportunity for students to interact with and peruse through additional literature. Most of the school texts at the middle school were only found in a central library. A library was toured at the elementary campus noting that books were class sets of leveled readers and not available for student self selection and entertainment.

All three settings sustained a very similar theme in regards to social responsibility to self, others, and the environment. Teachers followed a curriculum that was provided with rare deviation. Each of the elementary classes was 30 minutes in length while the middle school classes lasted for 45 minutes. All teachers were very punctual with their beginning and ending times. Therefore, as Chern (1999) noted in her study, the similarity of Chinese literacy instructional delivery to Bauman, et al.'s (1998) study that "portrayed American teachers; both Chinese and American teachers employed balanced instruction that reflected a whole-part-whole approach to integrate discrete language structure into holistic reading activities" (p. 26).

As the middle school students changed classes, they appeared carefree and not hurried, moving in a well-behaved fashion. The elementary school's classes were structured so that single-file movement coming and leaving the staged area was mandatory. However, after the delegation was served lunch, a student-led tour of the school revealed playful, proud, and boisterous students who were eager to share and entertain. The teachers allowed students to 
meander and playfully move from room to room during this time period to enjoy our visitations.

Another feature shared by the two schools was the morning exercises. All students (over 1000) line up in straight rows and columns to conduct routine exercises. Each school has an adult give the commands in Chinese. The exercises are not strenuous, mainly stretching, lunging, and bending that have become rote actions. The elementary students appear to have student leaders on stage, and a volunteer is selected to lead the group at different points during the program.

One more note of interest was in the notification of class ending. The middle school students heard loud ringing bells, as do many American students. However, the elementary students were notified of changing classes by sweet, melodic music. In our very limited cultural experience, the elementary students of our acquaintance usually heard only three bells for the day, beginning of school, the tardy bell, and the final bell of the day for dismissal.

It is important to note that as we were awed by the educational experience and cultural exchanges, the three short classroom documentations pale to a more in depth study. Shortcomings to this study include that it was not a long-term investigation. Additional studies could be conducted to align school comparisons for longer durations (observations for a semester), documenting observations and conducting interviews would also yield fruitful findings.

\section{Discussion}

This study commenced to determine how Chinese literacy instruction is similar and different to rural public school instruction in the United States. As preparations were made and research was conducted, more questions surfaced as to how the instructional methods that we have been acquainted work with such a diverse culture, whose language form in both speech and character is worlds apart to the language instruction of our familiarity. That combined with the political pressures for student success through a developed curriculum, teacher created versus governmentally mandated.

The binding factor that stretches across these countries is the students. Students from both sides of the globe are eager, receptive learners of their language and literacy. Combine that factor with another influential force of dedicated teachers who continually strive to give their energy to the structuring of the next generation of leaders, decision makers, creators, and responsible citizens. As the Reading and Literacy Delegation mingled among the vibrant Chinese educators, a strong bond with children in mind surfaced. Education regardless of national borders similar in some regards, as cultures and languages change. Whether rural teachers instruct in self-contained classrooms or Chinese teachers are departmentalized, the responsibilities, the continual effort to use best practices that are research-based, and the demands from society are all present and well rooted within the educational system. What cultural influences exist between the educational systems? China's ministry documents their practices are rooted in research from 70 countries including the United States to guide its educational leadership, each country has benefited from the other's educational studies; we can continue to grow in the realm of basic education. Each country is faced with challenges to improve the educational standards as a nation attempts to meet the growing educational demands from its people. So a sea apart or just across the river, educational concerns, efforts, methods, and successes ebb and flow with the swing of the pendulum.

\section{References}

Belenky, M., Clinchy, B., Goldberger, N., \& Tarule, J. (1986). Women's ways of knowing: The development of self, voice, and mind. New York: Basic Books.

Campbell, M. (2002). Constructing powerful voices: Starting points for policy based literacy assessment reform. Journal of Reading Education, 27, 17-23

Chern, C. L. (1999). Literacy instruction in Taiwan: Teachers' belief and their classroom practices. In C. Y. Mee, \& N. S. Moi (Eds.), Language instructional issues in Asian classrooms. Newark, DE: International Reading Association. pp. 16-28

Collins, M. D., \& Cheek, Jr., E. H. (2000). Assessing and guiding classroom reading instruction. New York: McGraw-Hill.

Creswell, J. (2003). Research design: Qualitative, quantitative, and mixed methods approaches (2nd ed.). Thousand Oaks, CA: Sage.

Heller, M. (2006). Telling stories and talking facts: First grader's engagements in a non-fiction book club. The Reading Teacher, 60(4), 358. http://dx.doi.org/10.1598/RT.60.4.5

Katz, L. (1987). The experience of personal change. Unpublished doctoral dissertation. Union Graduate School, Union Institute, Cincinnati, $\mathrm{OH}$. 
Li, H., \& Rao, N. (2005, October). Curricular and instructional influences on early literacy attainment: Evidence from Beijing, Hong Kong, and Singapore. International Journal of Early Years Education, 13(3), 235-253. http://dx.doi.org/10.1080/09669760500295870

Lincoln, Y., \& Guba, E. (1985). Naturalistic inquiry. Beverly Hills, CA: Sage.

Mee, C. Y., \& Moi, N. S. (Eds.). (1999). Language instructional issues in Asian classrooms. Newark, DE: International Reading Association.

Ministry of Education of the People's Republic of China. (2005). Basic education in China: A survey of the development of basic education. [Online] Available: http://www.moe.edu.cn/english/basic_b.htm (November 5, 2010)

No Child Left Behind: A Desktop Reference (2002). Washington, DC: Office of the Undersecretary. [Online] Available: http://ed.gov/offices/OESE/reference.html (January, 2006)

Patton, M. (1990). Qualitative evaluation and research methods (2nd ed.). Beverly Hills, CA: Sage.

People to People Ambassadors' Program Guide. (2006). Basic education in China and the US and their challenges. Beijing, China: China Education Association for International Exchange.

Smith, S. B., Baker, S., \& Oudeans, M. K. (2001). Making a difference in the classroom with early literacy instruction. Teaching Exceptional Children, 33(6), 8-14

Snow, C. (1991). The theoretical basis for relationships between language and literacy development. Journal of Research in Childhood Education, 6(1), 5-10. http://dx.doi.org/10.1080/02568549109594817

Stewart, M. T. (2004). Early literacy instruction in the climate of No Child Left Behind. The Reading Teacher, 57(8), 732-743

Strauss, A., \& Corbin, J. (1990). Basics of qualitative research: Grounded theory procedure and techniques. Newbury Park, CA: Sage.

Whitehurst, G., \& Lonigan, C. (1998). Child development and emergent literacy. Child Development, 69(3), 848-872

Williams, N. L., \& Bauer, P. T. (2006, September). Pathways to affective accountability: Selecting, locating, and using children's books in elementary school classrooms. The Reading Teacher, 60(1), 14-22. http://dx.doi.org/10.1598/RT.60.1.2

Yongbing, L. (2005). A pedagogy for digraphia: An analysis of the impact of Pinyin on literacy teaching in China and its implications for curricular and pedagogical innovations in a wider community. Language and Education, 19(5), 400-414. http://dx.doi.org/10.1080/09500780508668693 